\title{
Studies on Correlation and Path Coefficient Analysis in Rice (Oryza Sativa L.)
}

\author{
C.A. Sowmiya* and M. Venkatesan
}

\author{
Department of Genetics \& Plant Breeding, Faculty of Agriculture, Annamalai University, \\ Annamalai Nagar - 608 002, Tamil Nadu, India \\ *Corresponding author
}

\begin{tabular}{|c|c|}
\hline & A B S T R A C T \\
\hline $\begin{array}{l}\text { Genotypic } \\
\text { correlation } \\
\text { coefficient, } \\
\text { Phenotypic } \\
\text { correlation } \\
\text { coefficient } \\
\text { and path analysis. }\end{array}$ & \multirow{3}{*}{$\begin{array}{l}\text { The experiment was carried out to explore correlation and path coefficient analysis in } 48 \\
\text { rice genotypes for nine characters viz., days to first flower, plant height, number of tillers } \\
\text { per plant, number of panicles per plant, number of grains per panicle, panicle length, } \\
\text { thousand grain weight, grain L/B ratio and grain yield per plant. The genotypic correlation } \\
\text { coefficients showed higher magnitude than phenotypic correlation coefficients which } \\
\text { indicated masking or modifying effect of environment. The genetic correlation revealed } \\
\text { that grain yield per plant had strong negative and significant association with days to first } \\
\text { flower at both genotypic and phenotypic levels. So it could be inferred that grain yield and } \\
\text { days to first flower could be used as selection criteria for the improvement of grain yield } \\
\text { per plant. Scrutiny in path analysis indicated that maximum direct effect on grain yield was } \\
\text { exhibited by number of panicles per plant. Hence the trait should be taken in account of } \\
\text { breeding programme to develop the maximum of threshold yield obtaining new rice } \\
\text { varieties or hybrids. }\end{array}$} \\
\hline Article Info & \\
\hline $\begin{array}{l}\text { Accepted: } \\
\text { 21 August } 2017 \\
\text { Available Online: } \\
\text { 10 September } 2017\end{array}$ & \\
\hline
\end{tabular}

Introduction

Rice is a cereal crop belonging to genus Oryza of family Poaceae and tribe Oryzeae. The two cultivated rice species, Oryza sativa L. (Asian Rice) and Oryza glaberrima Steud, (African Rice), belongs to a species group called Oryza sativa complex together with the five wild taxa, $O$. rufipogon, $O$. longistaminata Chev. et Roehr., O. barthii A. Chev., $O$. glumaepatula Steud., and $O$. meridionalis $\mathrm{Ng}$.

The two major rice varieties grown world wide today are Oryza sativa indica and Oryza sativa japonica. Together with all circumstantial evidence, it is suggested that $O$. rufipogon is the ancestor of $O$. sativa.
Similarly, it leaves no doubt that $O$. barthii is the ancestor of African rice $O$. glaberrima.

It is an important cereal crop, grown under diverse agro - ecological conditions. It is also a major food crop, as it ranks second to wheat among the most cultivated cereals in the world. To feed the ever growing population, the targeted rice production of World, China and India for the year 2030 were envisaged as $771.02,168.90$ and 130.02 million tonnes respectively.

Correlation coefficient analysis measures the mutual relationship between various plant characters and determines the component 
characters on which selection can be based for genetic improvement in yield. Grain yield is a complex character and is the end - product of various traits. Therefore knowledge regarding the correlation of grain yield with other component characters is valuable for understanding the correlated response to selection for yield. Path coefficient analysis is helpful to recognize direct and indirect causes of correlation and also enables us to compare the causal factors on the genetic basis of their relative contributions. Hence the present study of correlation and path analysis would serve path for future breeding programmes.

\section{Materials and Methods}

The present day investigation was conducted at the Plant Breeding Farm, Department of Genetics and Plant Breeding, Faculty of Agriculture, Annamalai University, Annamalai Nagar, Tamil Nadu, India during 2015 - 2017. Seeds of forty eight genotypes (Table 1) were sown in raised nursery beds during February, 2016. In each genotype, one seedling per hill was transplanted in the main field after 25 days with spacing of $20 \mathrm{~cm} \mathrm{X}$ $20 \mathrm{~cm}$. The experiment was carried out in Randomized Block Design with three replications. As recommended, agronomic and plant protection measures were followed during the crop period. A uniform population of 12 plants in a row was maintained. Nine productive and quality characters viz., days to first flower, plant height, number of tillers per plant, number of panicles per plant, number of grains per panicle, panicle length, thousand grain weight, grain L/B ratio and grain yield per plant were recorded on single plant basis in eight randomly selected plants of each genotype per replication. The mean data were utilized for the statistical studies.

\section{Results and Discussion}

Direct selection for yield is not effective as yield is a complex and quantitatively inherited character with low heritability. Therefore, indirect selection could be made for the component characters contributing to yield through character association as it provides information about the characters that are correlated with each other in improving yield. Estimates of correlation between yield and yield component characters in rice genotypes are presented in table 2 .

A positive value of correlation shows that the changes of two variables are in the same direction, i.e., high value of one variable are associated with high values of the other and vice versa. The breeder is always concerned for the selection of superior genotypes on the basis of phenotypic expression. However, for the quantitative characters, genotypes are influenced by environment, thereby affecting the phenotypic expression. Information regarding the nature and extent of association of morphological characters would be helpful in developing suitable plant type, in addition to the improvement of yield a complex character for which direct selection is not effective. In general, the genotypic and the phenotypic correlation coefficients showed similar trend but genotypic correlation coefficients were of higher in magnitude than the corresponding phenotypic correlation coefficients which might be due to masking or modifying effect of environment (Singh, 1980).

In the present investigation, there was strong negative and significant correlation between grain yield per plant and days to first flower at both genotypic and phenotypic levels (Table 2 ). Thus negative correlation between grain yield and days to first flower indicated that grain yield per plant would be reduced when the genotypes had late flowering nature. Contrary findings were reported by Mohan et al., (2015) and Thippeswamy et al., (2016) in which they reported positive significant correlation between grain yield per plant and days to first flower at both levels. 
Also, days to first flower had positive significant correlation with plant height and negative significant correlation with grain yield per plant at genotypic and phenotypic levels. The results clearly indicated that long duration genotypes would be tall yet contribute less grain yield. Similar result was reported by Mohan et al., (2015) and Thippeswamy et al., (2016) reported that days to first flower had positive significant correlation with plant height at both levels.

Plant height had maximum correlations among all the characters studied for correlation coefficients. It had positive and significant correlation with number of tillers per plant, number of panicles per plant, number of grains per panicle and panicle length at both genotypic and phenotypic levels. Similar reports were reported by Vijay Kumar (2015) for significance and positive correlation in panicle length at phenotypic level, Thippeswamy et al., (2016) for positive significant correlation in panicle length and number of grains per panicle at both phenotypic and genotypic levels, Mohan et al., (2015) for positive significant correlation in panicle length at both levels whereas only at phenotypic level for number of grains per panicle, Ravindra Babu et al., (2012) for positive significant correlation in panicle length at both levels and number of panicles per plant at genotypic level, Yadav et al., (2011) for positive significant correlation in panicle length at both levels and Singh et al., (2014) for positive significant correlation in panicle length, number of tillers per plant and number of grains per panicle at both levels.

Table.1 List of genotypes selected for analysis

\begin{tabular}{|l|l|l|l|}
\hline SL. No & \multicolumn{1}{|c|}{ Name of genotype } & SL. No & Name of genotype \\
\hline 1. & ADT 47 & 2. & Geetanjali \\
\hline 3. & ADT 41 & 4. & IET 14348 \\
\hline 5. & ADT 37 & 6. & Jaya Mathi \\
\hline 7. & ADT 36 & 8. & Samba Mashuri \\
\hline 9. & ADT 45 & 10. & MTU 1156 \\
\hline 11. & ADT 48 & 12. & MTU 7029 \\
\hline 13. & ADT 43 & 14. & MTU 1121 \\
\hline 15. & ADT 42 & 16. & Super Amman \\
\hline 17. & ASD 16 & 18. & AngurSelam \\
\hline 19. & ASD 18 & 20. & ASD 1 \\
\hline 21. & IR 66 & 22. & STBN 18 \\
\hline 23. & IR 64 & 24. & Bhavani \\
\hline 25. & IR 72 & 26. & PLA 1100 \\
\hline 27. & IR 50 & 28. & MTU 1010 \\
\hline 29. & TPS 5 & 30. & K. Sona \\
\hline 31. & PMK 3 & 32. & AVT 1303 \\
\hline 33. & AVT 1320 & 34. & CO 47 \\
\hline 35. & AVT 1302 & 36. & TRY 2 \\
\hline 37. & AVT 1321 & 38. & TKM 9 \\
\hline 39. & Kullakar & 40. & MDU 5 \\
\hline 41. & Pooughar & 42. & PY 3 \\
\hline 43. & IR 36 & 44. & Dhanya Lakshmi \\
\hline 45. & NLR 34449 & 46. & IR 20 \\
\hline 47. & Akshaya & 48. & CO 51 \\
\hline
\end{tabular}


Table.2 Phenotypic and genotypic correlation coefficients among yield attributing characters in rice genotypes

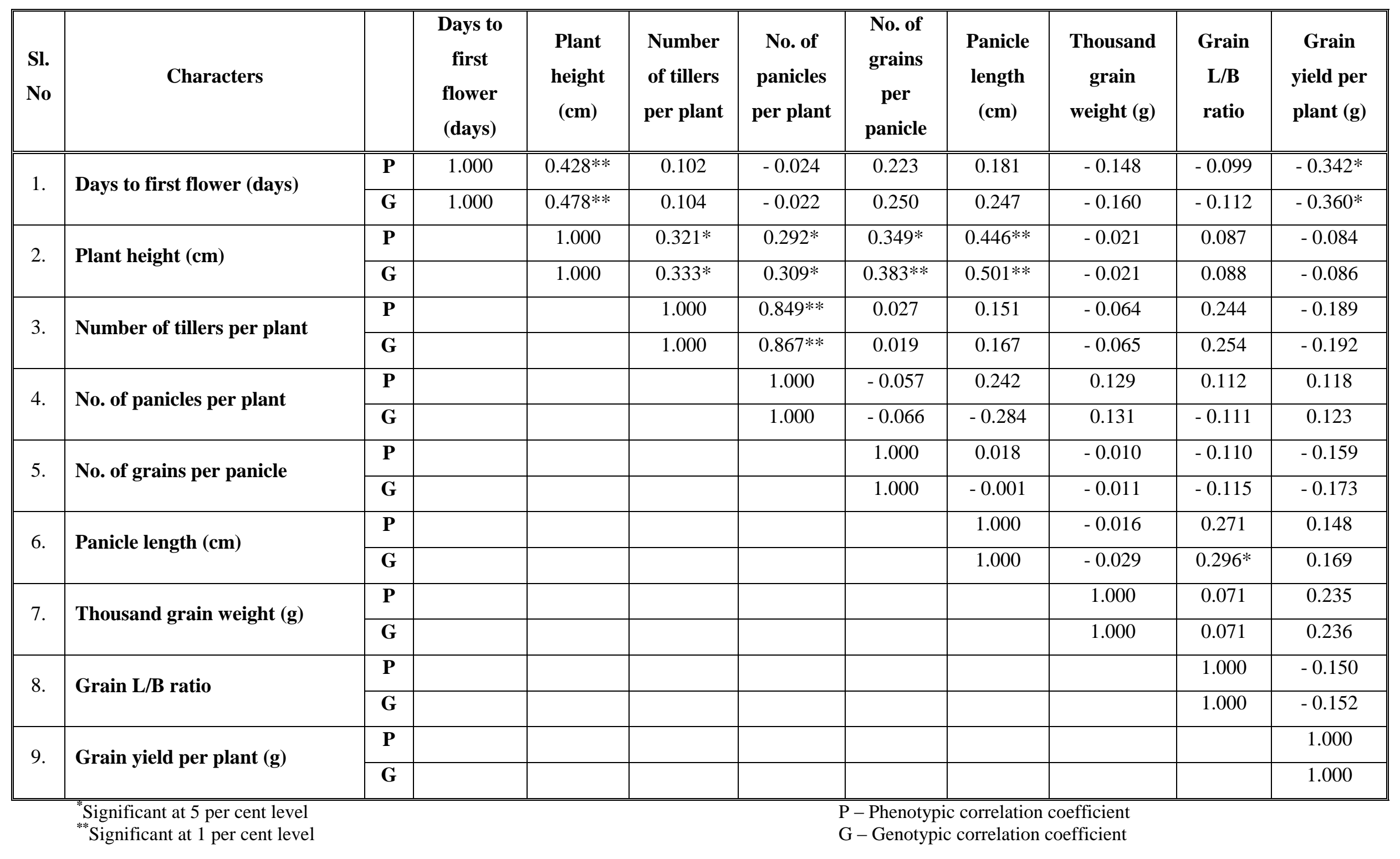


Table.3 Path coefficient analysis showing direct and indirect effects of yield attributing characters on Grain yield per plant in rice genotypes

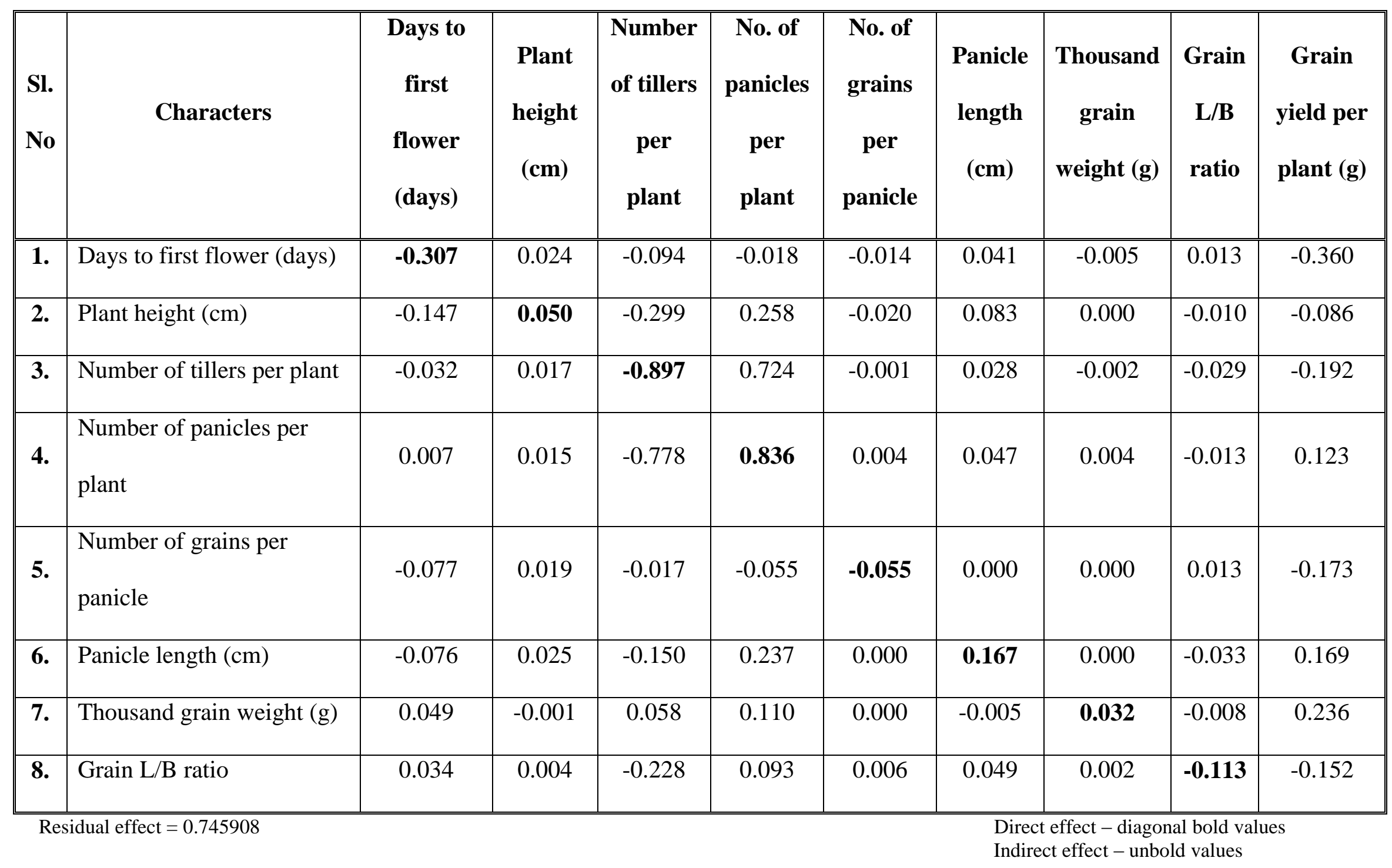


From the investigation, number of tillers per plant showed significant positive correlation with number of panicles per plant at both genotypic and phenotypic levels. Yadav et al., (2011) also conveyed the same result.

Panicle length showed significant positive correlation with grain L/B ratio at genotypic level only. From the above discussion, it may be seen that selection of these characters would ultimately help in identifying genotypes with high yield potential.

Path coefficient analysis allows separating the direct and indirect effects through other contributes by apportioning the correlations (Wright, 1921) for better interpretation of cause and effect relationship. The results clearly showed significant difference in genotypic and phenotypic direct and indirect effects, indicating the predominance of environmental influence in expression of the traits. The direct and indirect contribution of various characters on yield in rice genotypes are measured and are presented in table 3 .

In the present investigation, the residual effect was 0.745908 . Perusal of results obtained in path analysis revealed that high direct effect on grain yield was exhibited by number of panicles per plant. Similar result was reported by Ravindra Babu et al., (2012) whereas contrary reports were given by Thippeswamy et al., (2016), Mohan et al., (2015), Yadav et al., (2011) and Akhtar et al., (2011).

Panicle length recorded low positive direct effect on grain yield per plant, which was reported as same by Ravindra Babu et al., (2012).

The trait, number of tillers per plant and days to first flower had high negative direct effect on grain yield per plant. Similar report was given by Mohan et al., (2015) and Rajamadhan et al., (2011) for days to first flower and Akhtar et al., (2011) for number of tillers per plant.

In addition to the direct effects, indirect effect of number of tillers per plant via number of panicles per plant was high and positive on grain yield per plant was also observed. Similar finding was reported by Yadav et al., (2011).

Moderate positive indirect effect was observed by plant height through number of panicles per plant on grain yield per plant. But Ravindra Babu et al., (2012) and Yadav et al., (2011) reported positive low indirect effect on grain yield for the same.

Plant height also had moderate negative indirect effect on grain yield through number of tillers per plant yet it was recorded as negligible effect by Yadav et al., (2011).

Also, panicle length was detected to have moderate positive indirect through number of panicles per plant on grain yield. Similar reports were reported by Basavaraj et al., (2011) and Rajamadhan et al., (2011). Grain $\mathrm{L} / \mathrm{B}$ ratio had also observed moderate negative indirect effect through number of tillers per plant on grain yield per plant.

From the above discussion, it was inferred that the pattern of path coefficient observed in the present study was in agreement with the correlation obtained. In general, the character days to first flower recorded negative significant correlation and high negative direct effect with grain yield per plant. Hence it could be used as selection criteria in breeding programme to develop high yielding new plant type rice varieties.

\section{References}

Akhtar, N., M. F. Nazir, A. Rabnawaz, T. Mahmood, M. E. Safdar, M. Asif and 
A. Rehman. 2011. Estimation of Heritability, Correlation and Path Coefficient Analysis in fine grain Rice (Oryza sativa L.). The Journal of Animal \& Plant Sciences, 21(4): 660664.

Basavaraj, T.S., Ganagaprasad, B.M. Dhusyantha Kumar and Shilaja Hittlamani. 2011. Correlation and path analysis of yield and yield contributes in local rice cultivars (Oryza sativa L.). Electronic J. Plant Breed., 523-526.

Mohan, Y.C., S. Thippeswamy, K. Bhoomeshwar, B. Madhavilatha and Jameema Samreen. 2015. Diversity analysis for yield and gall midge resistance in rice (Oryza sativa L.) in Northern Telangana zone, India. SABRAO J. of Breed. and Genet., 47(2): 160-171.

Rajamadhan, R., R. Eswaran and A. Anandan. 2011. Investigation of correlation between traits and path analysis of rice (Oryza sativa L.) grain yield under coastal salinity. Electronic J. of Plant Breed., 2(4): 538-542.

Ravindra Babu, V., K. Shreya, Kuldeep Singh Dangi, G. Usharani and A. Siva Shankar. 2012. Correlation and Path Analysis Studies in Popular Rice hybrids in India. Intl. J. of Scientific and Res. Publications, 2(3): 1-5.

Singh, A.K., R. Nandan and P.K. Singh. 2014. Genetic variability and association analysis in rice germplasm under rainfed conditions. Crop Res., 47(1, 2 \& 3): 7-14.

Singh, R.P., 1980. Association of grain yield and its component in $F_{1}$ and $F_{2}$ population of rice. Oryza, 17: 200-204.

Thippeswamy, S., Y. Chandramohan, B. Srinivas and D. Padmaja. 2016. Selection of diverse parental lines for heterotic hybrid development in rice (Oryza sativa L.). SABRAO J. of Breed, and Genet, 48(3): 285-294.

Vijay Kumar, 2015. Genetic diversity and character association studies for some economic traits in rice (Oryza sativa L.). An Intl. Quarterly J. of Life Sci., 10(2): 899-904.

Wright, S., 1921. Correlation and association. J. Agric. Res., 20: 550-587.

Yadav, S.K., P. Pandey, B. Kumar and B.G. Suresh. 2011. Genetic Architecture, Inter-relationship and selection criteria for yield improvement in rice (Oryza sativa L.). Pakistan J. of Biological Sci., 14(9): 540-545.

\section{How to cite this article:}

Sowmiya, C.A. and Venkatesan, M. 2017. Studies on Correlation and Path Coefficient Analysis in Rice (Oryza Sativa L.). Int.J.Curr.Microbiol.App.Sci. 6(9): 1757-1763. doi: https://doi.org/10.20546/ijcmas.2017.609.217 